\title{
Temperature and deaths from ischaemic heart disease
}

\author{
DAVID BAINTON, FRED MOORE, AND PETER SWEETNAM
}

From the Medical Research Council, Epidemiology Unit, Cardiff

SUMMARY Certain features of the relationship between 11 measurements of weekly temperature and the number of deaths from ischaemic heart disease (IHD) within age groups in Greater London between 1970 and 1974 are described. Firstly, the correlation coefficients between age-specific deaths from IHD and each of the temperature variables are of a similar order. Secondly, in contrast, the linear regression coefficients between deaths and temperature are more variable and depend upon the particular measurement of temperature chosen. Thirdly, the proportional changes in the number of deaths with the temperature variables are similar within specific age groups; consequently it is suggested that deaths from IHD and temperature may be directly related.

As part of a detailed examination of the effect of influenza on deaths from ischaemic heart disease, which is not further discussed here, an initial study was made of the relationship between temperature and deaths from ischaemic heart disease (IHD). The purpose of this preliminary study was to examine the correlations between death from IHD and various summary temperatures in which the unit of time was one week. We report here certain features relevant to this association with environmental temperature and discuss whether there is a causal relationship.

\section{Methods}

Boyd (1960) described the disturbing effects of influenza on the relationship of deaths from arteriosclerotic heart disease and temperature, and thus we tried to use for this study a period of time which was relatively 'flu-free'. As we wished to use the 8th Revision of the International Classification of Diseases (1967) with its extensive revision in the coding of deaths from arteriosclerotic heart disease the study period had to be after 1967. The four-year period July 1970 to June 1974 went some way to satisfying these two conditions. There was no major influenza epidemic during this time although there were two small outbreaks, as judged by deaths from influenza (ICD 470-474, 8th Revision) during the winters of 1971-72 and 1972-73.

For each week, from July 1970 to June 1974, the number of deaths assigned to B 28 (ICD 410-414, 8th Revision) for the age groups 45 to 54,55 to 64 , 65 to 74, 75 and over, and for all ages for Greater London was extracted from the Registrar General's
Weekly Return. The Return gives the number of deaths notified in a particular week, and not the number of deaths occurring during that period. For that same four-year period and same working week (Saturday to Friday) the following temperatures for each day at Heathrow airport were abstracted from the Daily Weather Report as published by the Meteorological Office:

Temperature at 00 hours

06 hours

12 hours

18 hours

Maximum temperature recorded during the day $(9.00$ to 21.00$)$

Minimum temperature recorded during the night (21.00 to 9.00$)$

From these six daily readings, various summary temperatures for each week were calculated-for example, mean maximum, mean minimum. In all 11 summary temperatures were derived which are shown in the Appendix.

From these data a correlation matrix and a table of regression coefficients for deaths from IHD on temperature were obtained. These coefficients were calculated, not only for the relationship between deaths with measurements of temperature for the same week but also with temperatures for the two preceding weeks, to examine the possible effect of previous experience upon mortality.

In order to obtain a measurement of the proportional increase in deaths from IHD with decreasing temperature the data were plotted on a semilogarithmic scale (with deaths from IHD being plotted on the log scale), and regression coefficients 
for these log values on temperature were obtained. This was done for three of the summary temperatures. A constant regression coefficient for the data plotted in this way for the different age groups would imply a constant proportional increase in deaths.

\section{Results}

THE DATA

Figure 1 shows the mean weekly temperature from July 1970 to June 1974 and also the number of deaths in Greater London from IHD for age groups 45 to 54,55 to 64,65 to 74 , and 75 and over. The cyclical pattern of deaths from IHD is clearly seen especially in older age groups. In Fig. 2 the same data plotted as a scatter diagram, suggest that there is a reasonably linear relationship for the association between number of deaths at all ages with mean weekly temperature.

Correlation coefficients

Table 1 shows the range of the correlation $\vec{\circ}$ coefficients between number of deaths at specified
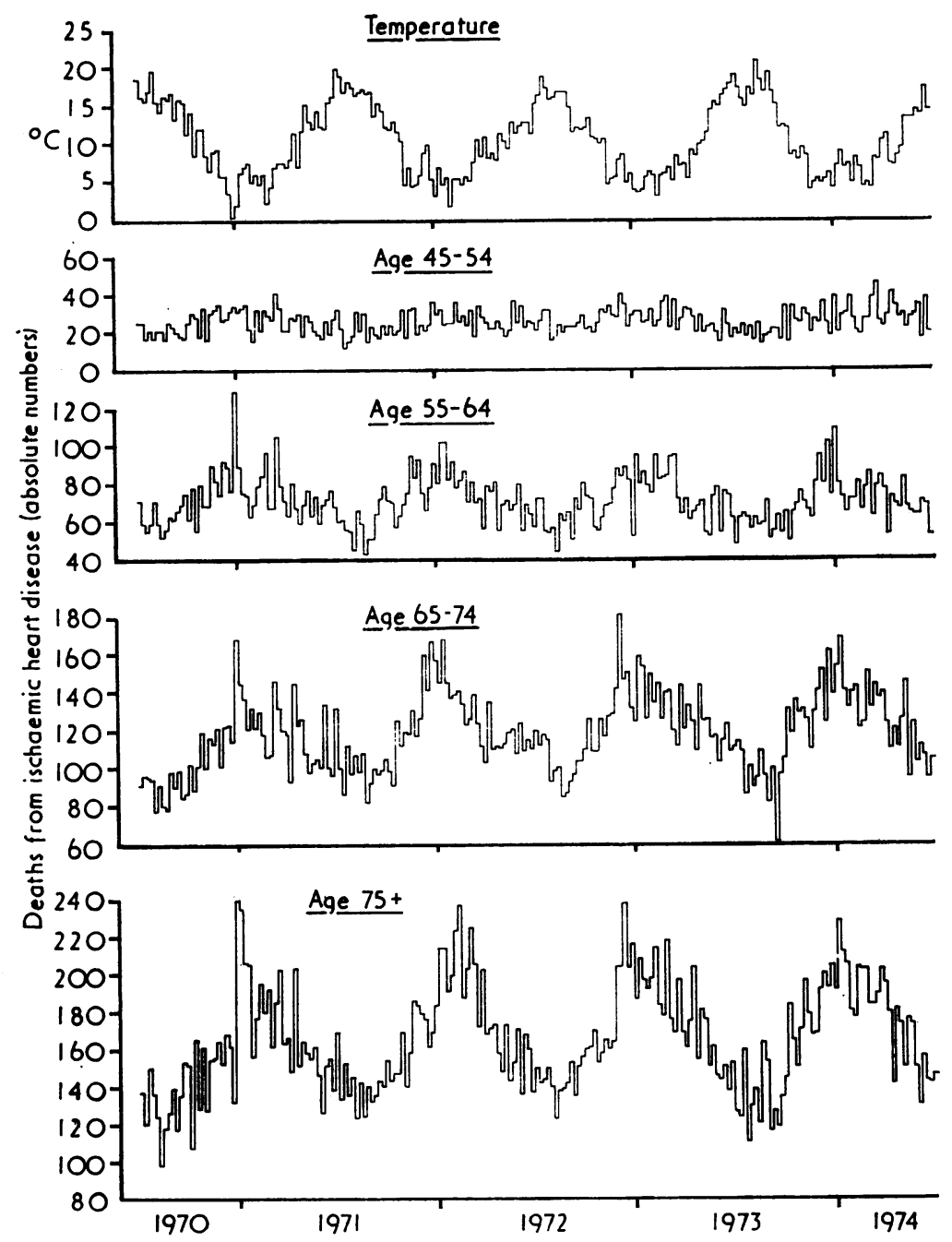

Fig. 1 Deaths each week from ischaemic heart disease (ICD 410-414) in Greater London, and mean weekly temperatures* at Heathrow airport during the four years July 1970 to June 1974.

$$
\text { *calculated as mean of } \sum_{7 \text { days }} \frac{(00+06+12+18)}{28}
$$




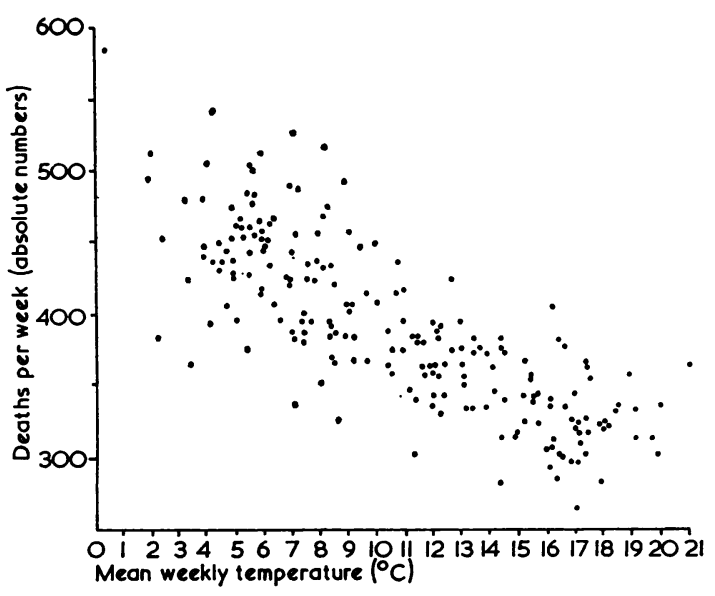

Fig 2. Scatter diagram of same data as in Fig. 1 (all ages).

Table 1 Range of correlation coefficients for numbers of deaths from IHD and 11 temperature variables, by week

\begin{tabular}{llll} 
& $\begin{array}{l}\text { Age } \\
\text { (years) }\end{array}$ & $\begin{array}{l}\text { Correlation } \\
\text { coefficient }\end{array}$ \\
\hline Same week & $45-54$ & -0.376 & -0.427 \\
& $55-64$ & -0.584 & -0.633 \\
& $65-74$ & -0.683 & -0.746 \\
& $75+$ & -0.712 & -0.758 \\
Lagged one week & All ages & -0.760 & -0.813 \\
& $45-54$ & -0.399 & -0.479 \\
& $55-64$ & -0.617 & -0.656 \\
Lagged two weeks & $65-74$ & -0.691 & -0.769 \\
& $75+$ & -0.757 & -0.810 \\
& All ages & -0.800 & -0.851 \\
& $45-54$ & -0.417 & -0.470 \\
& $55-64$ & -0.559 & -0.620 \\
& $65-74$ & -0.673 & -0.741 \\
& $75+$ & -0.712 & -0.780 \\
& All ages & -0.754 & -0.826 \\
\hline
\end{tabular}

ages with 11 temperature variables for the same week as the deaths and for each of the two preceding weeks. The correlation coefficients for each temperature variable increased progressively with increasing age. The correlation coefficients for both individual age groups and for all ages were consistent from year to year. All 11 temperature variables produced correlation coefficients of a similar order within each age group studied-the range being approximately 0.06 between the highest and lowest correlation coefficients. This was true irrespective of age group, year, or whether the data were lagged or not.

In order to test the consistency of the correlation coefficients, the various weekly summary temperatures were placed in rank order and coefficients of concordance were derived. Table 2 shows that although the range for the correlation coefficients was only of the order of 0.06 , yet within this narrow band the rank order of the
Table 2 Coefficients of concordance for 11 correlation coefficients ranked in order of size for temperature and deaths from IHD. (Temperature and deaths relate to the same week)

\begin{tabular}{lccc}
\hline Within age group/between year & \multicolumn{2}{l}{ Within year/between age group } \\
\hline $45-54$ & 0.389 & $1970 / 71$ & 0.438 \\
$55-64$ & 0.653 & $1971 / 72$ & 0.766 \\
$65-74$ & 0.533 & $1972 / 73$ & 0.739 \\
$75+$ & 0.688 & $1973 / 74$ & 0.284 \\
All ages & 0.740 & $1970 / 74$ & 0.801 \\
\hline
\end{tabular}

correlation coefficients remained consistent when examined both within year/between age groups and within age group/between years. The temperature which gave consistently the highest correlation was the mean temperature at 12 noon. The weakest correlations were provided by the mean 06 hours temperature, the mean minimum and the absolute minimum for the week.

\section{Regression coefficients}

Table 3 is similar to Table 1 and shows the range in the regression coefficients for the number of deaths in specific age groups on 11 temperature measurements for the same week as the deaths and for the two preceding weeks. The regression coefficients increased in size with increasing age. Within each age group, however, the largest regression coefficient was approximately $50 \%$ greater than the smallest-for example, the regression coefficient for deaths from IHD (all ages) ranged from $7 \cdot 680$ to $11 \cdot 141$. These coefficients corresponded respectively with the absolute maximum temperature and the mean temperature at 06 hours, for the week.

In a similar manner to that for the correlation coefficients, coefficients of concordance were obtained for the 11 regression coefficients when ranked in order. Table 4 shows the high value of these

Table 3 Range of regression coefficients for numbers of deaths from IHD on 11 different temperature variables, by week

\begin{tabular}{llll}
\hline & $\begin{array}{l}\text { Age } \\
\text { (years) }\end{array}$ & $\begin{array}{l}\text { Regression } \\
\text { coefficient }\end{array}$ \\
\hline Same week & $45-54$ & -0.446 & -0.616 \\
& $55-64$ & -1.305 & -1.890 \\
& $65-74$ & -2.447 & -3.468 \\
& $75+$ & -3.428 & -5.054 \\
Lagged one week & All ages & -7.680 & $-11 \cdot 141$ \\
& $45-54$ & -0.417 & -0.722 \\
& $55-64$ & -1.324 & -2.040 \\
Lagged two weeks & $65-74$ & -2.432 & -3.503 \\
& $75+$ & -3.513 & -5.402 \\
& All ages & -7.756 & -11.757 \\
& $45-54$ & -0.443 & -0.738 \\
& $55-64$ & -1.267 & -1.821 \\
& $65-74$ & -2.413 & -3.416 \\
& $75+$ & -3.464 & -4.992 \\
& All ages & -7.679 & -11.050 \\
\hline
\end{tabular}


Table 4 Coefficients of concordance for 11 regression coefficients ranked in order of size for deaths from IHD on temperature. (Temperature and deaths relate to the same week.)

\begin{tabular}{lccc}
\hline Within age group/between year & \multicolumn{2}{l}{ Within year/between age group } \\
\hline $45-54$ & 0.585 & $1970 / 71$ & 0.973 \\
$55-64$ & 0.976 & $1971 / 72$ & 0.663 \\
$65-74$ & 0.920 & $1972 / 73$ & 0.933 \\
$75+$ & 0.960 & $1973 / 74$ & 0.966 \\
All ages & 0.969 & $1970 / 74$ & 0.989 \\
\hline
\end{tabular}

coefficients. Temperatures which gave consistently the highest regression coefficients were the mean value at midnight, the mean value at 06 hours, and the mean minimum for the week. Those giving the lowest regression coefficients were the mean value at 18 hours, the mean maximum, and the absolute maximum for the week.

The weekly summary temperatures which gave the highest regression coefficients were those characterising the 'colder' parts of the week-for example, the mean minimum and the mean value at 06 hours. This is because over a year there is a narrower range of temperature for the colder indices-for example, mean minimum or mean temperature at 06 hours-than there is for the warmer indices such as the absolute maximum or mean maximum.

\section{Proportional changes with decreasing temperature}

Table 5 shows the regression coefficients for the $\log _{10}$ of the number of deaths on certain measurements of temperature for the same week which are similar for all the age groups. Thus the proportional changes in numbers of deaths from IHD on temperature are virtually the same for all age groups.

Table 5 Regression coefficients for deaths from IHD on temperature when deaths are plotted on a $\log _{10}$ scale

\begin{tabular}{|c|c|c|c|}
\hline $\begin{array}{l}\text { Age } \\
\text { (years) }\end{array}$ & $\begin{array}{l}\text { Mean } \\
\text { maximum }\end{array}$ & $\begin{array}{l}\text { Mean } \\
\text { daily* }\end{array}$ & $\begin{array}{l}\text { Mean } \\
\text { minimum }\end{array}$ \\
\hline $\begin{array}{l}45-54 \\
55-64 \\
65-74 \\
75+ \\
\text { All ages }\end{array}$ & $\begin{array}{l}0 \cdot 0078 \\
0 \cdot 0085 \\
0 \cdot 0098 \\
0 \cdot 0097 \\
0 \cdot 0093\end{array}$ & $\begin{array}{l}0.0094 \\
0.0102 \\
0.0118 \\
0.0118 \\
0.0112\end{array}$ & $\begin{array}{l}0.0103 \\
0 \cdot 0111 \\
0 \cdot 0129 \\
0 \cdot 0130 \\
0 \cdot 0123\end{array}$ \\
\hline
\end{tabular}

\section{Discussion}

The size of the correlation coefficients for deaths from IHD and temperature for the 11 temperature variables did not differ to any great extent. The effect of lagging by one week is to increase marginally the size of the correlation coefficient, but this effect diminishes if the time lag is increased to two weeks. Boyd (1960) also found that the $\stackrel{0}{?}$ effect of lagging deaths by one week resulted in the highest correlation coefficient as compared with $\stackrel{5}{\stackrel{9}{+}}$ that derived when both temperature and deaths from IHD refer to the same week or the coefficient $\frac{\bar{O}}{\bar{D}}$ derived when deaths are lagged by two or more weeks. $\frac{\bar{D}}{\vec{D}}$

Although the choice of a particular temperature $\stackrel{\mathbb{Q}}{\Omega}$ to characterise a week may make a marked difference $\$$ to the linear regression coefficient of deaths on $\overrightarrow{0}$ temperature from IHD yet the high values for the coefficients of concordance suggest a constancy in the $\vec{\omega}$ degree of association between these two variables.

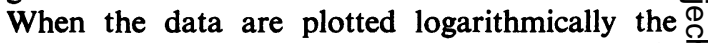
regression coefficients are of a similar magnitude $\stackrel{\vec{\omega}}{\vec{\omega}}$ for all age groups, and thus the proportional change in deaths from IHD as the temperature $\overrightarrow{.}$ decreases is of a similar order irrespective of age. 0 Anderson and Le Riche (1970) have suggested that the relationship of temperature with deaths from IHD is indirect and is generated by the allocation 3 of deaths by doctors certifying the cause as being $\frac{\widehat{N}}{3}$ due to IHD rather than to respiratory disease in $\supset$ patients in whom both diseases existed. That is, in $\overrightarrow{0}$ those with chronic IHD who die of an intercurreof. respiratory infection, the primary cause is like to be attributed to the heart disease, although it is the respiratory infection that is directly related to temperature. Bull (1973) suggested that both IHD and respiratory infection are independently related $\stackrel{\circ}{D}$ to temperature. The results of the current study are relevant to this discussion and the fact that the $\stackrel{ }{3}$ proportional changes with declining temperature are of a similar order in both young and old suggests that its relationship is a direct one. Furthermore, the knowledge that the validity of $\stackrel{\odot}{\circ}$ certification of cause of death in younger subjects? is of a higher order than in the elderly (Heasman 3 and Lipworth, 1966) would add credence to this hypothesis.

Our findings support those of Rogot (1974) who showed that proportional changes for two age $\frac{9}{\triangle}$ groups, those 65 and over and those under 65 , were $\frac{D}{O}$ similar. The evidence presented here does not reject the indirect explanation claimed by Anderson and $N$ Le Riche (1970) but it does lend weight to a more direct causal association.

We thank David Clayton, Department of Clinical Epidemiology, Royal Free Hospital, London NW3 for his helpful advice and comments.

Reprints from David Bainton, MRC Epidemiology Unit, 4 Richmond Road, Cardiff CF2 3AS. 


\section{References}

Anderson, T. W., and Le Riche, W. H. (1970). Cold weather and myocardial infarction. Lancet, 1, 291-296.

Boyd, J. T. (1960). Climate, air pollution, and mortality. British Journal of Preventive and Social Medicine, 14, 123-135.

Bull, G. M. (1973). Meteorological correlates with myocardial and cerebral infarction and respiratory disease. British Journal of Preventive and Social Medicine, 27, 108-113.

Heasman, M. A., and Lipworth, L. (1966). Accuracy of Certification of Death: Studies on Medical and Population Subjects, No. 20. HMSO: London.

Rogot, E. (1974). Associations between coronary mortality and the weather, Chicago, 1967. Public Health Reports (Washington), 89, 330-338.

World Health Organisation (1967). International Classification of Diseases, 8th revision. WHO: Geneva.
Appendix

The summary temperatures derived for each week, Saturday to Friday were:

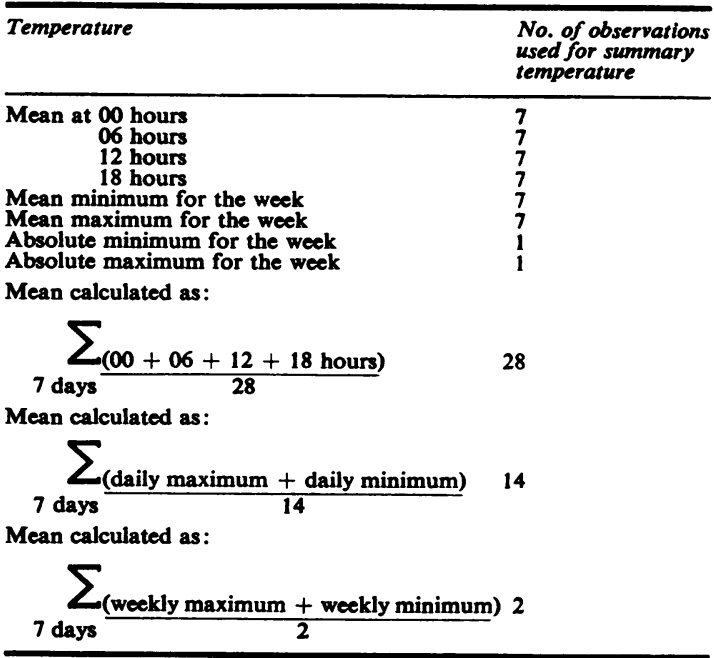

